\title{
O efeito de alginatos incorporados à ração sobre o desempenho produtivo e manejo de juvenis de tilápia do Nilo
}

\section{The effect of alginate incorporated in the ration on performance and handling of juvenile Nile tilapia Silage}

\author{
Julio Hermann Leonhardt ${ }^{1 *}$; Creusa Maria Rodrigues Leonhardt ${ }^{2}$;Leonardo \\ Cericato $^{3}$; Rodrigo Zanolo ${ }^{4}$
}

\begin{abstract}
Resumo
Os ácidos algínicos são extraídos de algas marinhas e quando utilizados na dieta dos peixes podem induzir respostas imunomoduladoras e imunoestimulantes. Este trabalho teve o objetivo de avaliar o efeito dos alginatos incorporado na ração sobre o desempenho produtivo e manejo de juvenis de tilápia do Nilo, Oreochromis niloticus. A primeira fase do experimento ocorreu em dois viveiros escavados de terra. Foram utilizados 57.000 juvenis de tilápia do Nilo, variedade local com peso médio de 14 gramas. Os Juvenis do viveiro experimental receberam ração tratada com ergosan na dose de $1 \%$ da dieta. A taxa de sobrevivência dos peixes e a conversão alimentar dos peixes alojados no viveiro experimental foi superior ao daqueles alojados no viveiro controle. Na segunda fase foram utilizados 54.126 juvenis de 40,63 gramas. Estes peixes foram transferidos para 16 tanques-rede. Não houve diferenças significativas de taxa de mortalidade dos peixes entre os tratamentos. A maior mortalidade ocorreu entre o terceiro e sétimo dias após o manejo. Os dados confirmam que a transferência de juvenis de tilápia do Nilo de viveiros de terra para tanques-rede é um agente estressor.
\end{abstract}

Palavras-chave: Ergosan. Estresse. Oreochromis niloticus. Tanques-rede.

\begin{abstract}
The alginic acid is extracted from seaweed and when used in fish ration may induce immunomodulatory and immunostimulants responses. This study aimed to evaluate the effect of alginic acid incorporated in the ration on performance and handling of juvenile Nile tilapia, Oreochromis niloticus. The first phase of the experiment occurred in two excavated ponds earth. 57,000 juveniles were used for Nile tilapia, local strains with the average weight of 14 grams. The juvenile Nile tilapia received the experimental diet treated with ergosan at a dose of $1 \%$ of the diet. The survival rate of fish and feed conversion in the experimental Nile tilapia was higher than the control Nile tilapia. In the second stage 54,126 juveniles with average weight 40.63 grams, were used. These fish were transferred to 16 fish cages. There were no significant differences in mortality rate between treatments. The highest mortality occurred between the third and seventh days after the handling. The data confirm that the transfer of juvenile Nile tilapia in the ponds to fish cages is a strong stressor.
\end{abstract}

Key words: Ergosan. Fish cages. Oreochromis niloticus. Stress.

${ }_{1}$ Prof. Dr. Departamento de Ciências Fisiológicas, Área de Aquicultura e Piscicultura, Centro de Ciências Biológicas, Universidade Estadual de Londrina, UEL, Londrina, PR. E-mail: leonhard@uel.br

2 Bióloga, Técnica da Piscicultura Matão, PR.E-mail: creusa_creu@hotmail.com

3 Médico Veterinário, Doutor em Aquicultura pelo CAUNESP, SP. E-mail: leonardo.cericato@intervet.sp.com

${ }^{4}$ Médico Veterinário, Mestre pela Universidade Estadual de Londrina, UEL, Londrina, PR. E-mail: rodrigo.zanolo@sp.intervet. com

* Autor para correspondência 


\section{Introdução}

A tilápia tornou-se o segundo peixe mais importante da aqüicultura mundial, perdendo somente em produção para as carpas. Com uma produção estimada de 1.700 .000 toneladas em 2007, a tilápia ultrapassou recentemente a produção mundial dos salmonídeos (FAO, 2007). Devido ao seu tamanho, rápido crescimento $\mathrm{e}$ palatabilidade, a tilápia tem se tornado o foco de muitos empreendedores, especialmente a espécie Oreochromis niloticus. Estes peixes constituem excelente fonte de proteína, e vários projetos artesanais e comerciais para o cultivo desta espécie têm sido desenvolvidos em diversos países tropicais (BEVERIDGE; MCANDREW, 2000; CYRINO et al., 2004; BARCELLOS, 2006).

O Brasil reúne condições extremamente favoráveis à piscicultura e ao cultivo da tilápia do Nilo. Sendo assim, apresenta grande potencial de mercado consumidor, clima favorável ao cultivo da espécie, boa disponibilidade de áreas para implantação de viveiros escavados e tanques-rede, grande safra de grãos que geram matéria prima para as rações e um grande potencial hídrico ainda pouco explorado pela aqüicultura (KUBITZA, 2000; MEURER; HAYASHI; BOSCOLO, 2003; BARCELLOS, 2006).

O manejo de peixes desencadeia uma série de mecanismos estressores, ocorrendo mecanismos de adaptação nervosa, imunológica e hormonal nos animais com um custo metabólico associado a esta adaptação. As respostas primárias e secundárias incluem aumentos de freqüência cardíaca, de fluxo sanguíneo branquial e da taxa metabólica com diminuição de cloretos de sódio e potássio plasmático. Como mecanismo terciário ocorre diminuição da resistência às doenças e redução na taxa de crescimento, na capacidade reprodutiva, tolerância térmica e tolerância a hipóxia. O estresse pode induzir 'a resposta de imunossupressão e resultar na instalação de doenças e mortalidade de peixes (BARCELLOS, 1999; PAVANELLI;
EIRAS; TAKEMOTO, 2002; BARCELLOS, et al., 2004; HARMON, 2009).

Nos últimos anos, tem crescido o interesse científico na investigação e identificação de compostos com atividades biológicas oriundas de organismos aquáticos e dentre esses compostos, os imunoestimulantes podem ser citados. Essas substâncias têm sido cada vez mais utilizadas na aqüicultura, devido à grande variedade de parasitas, fungos, bactérias e vírus que afetam a produção dos organismos aquáticos (TINMAN; KELVIN; CARVALHO-FILHO, 2000; BARBER, 2007).

Sistemas intensivos de cultivo de peixes estão marcados por elevadas taxas de mortalidade e a maior parte dessas mortes está relacionada com bactérias oportunistas presente na flora aquática (HUTTENHUIS et al., 2006). Diante disto, devem-se desenvolver estratégias para controlar estes patógenos, melhorando a saúde dos peixes. Para este fim, existem muitas substâncias a serem administradas, tais como os alginatos, os $\beta$-glucanos, produtos bacterianos, polissacarídeos entre outros, que podem ativar os mecanismos de defesa dos mesmos (BRICKNELL; DALMO, 2005).

Os imunoestimulantes previnem doenças em peixes, podendo ser muito úteis na aqüicultura. Sakai (1999) relatou diversos trabalhos sobre o uso de imunoestimulantes em peixes. Esses compostos ativam, principalmente, a função fagocítica das células de defesa e elevam suas atividades bacteriostáticas. A ativação das funções imunológicas está associada ao aumento da proteção contra doenças infecciosas a diversos patógenos. Além disso, o tratamento preventivo com imunoestimulantes naturais evita os problemas de resistência microbiológica, acúmulo de resíduos nos animais e poluição ambiental causada pelo uso indiscriminado de antibióticos e outras substâncias químicas (PARK; JEONG, 1996; VADSTEIN, 1997).

O uso de alginatos na piscicultura é um meio efetivo para aumentar a imunocompetência e a 
resistência às doenças no salmão, linguado do atlântico, robalo, truta e carpa comum (PEDDIE; ZOU; SECOMBES, 2002; SKJERMO; BERGH, 2004; BAGNI et al., 2005; CARNEVALI; SMITH; GIOACCHINI, 2006; HUTTENHUIS et al., 2006, respectivamente). Porém, pouco se sabe quanto a sua eficácia, limitação de uso e resposta para a tilápia do Nilo.

O ergosan é um extrato obtido das macroalgas marinhas Laminaria digitata e Ascophyllum nodosum (SCHERING-PLOUGH Animal Health Corp, 2009).Apresenta efeito positivo para tolerância ao stress de manejo e na resposta 'a vacinação em trutas Oncorhynchus mykiss (GIOACCHINI et al., 2008).

Os alginatos são conhecidos como indutores de resposta imune não específica a uma série de patógenos, e desta forma, capazes de fortalecer os sistemas de defesas naturais dos peixes a manejos estressores (BAGNI et al., 2005). Este trabalho teve o objetivo de avaliar o efeito do ergosan incorporado na ração sobre o desempenho produtivo e o manejo de juvenis de tilápia do Nilo, Oreochromis niloticus.

\section{Material e Métodos}

A primeira fase do experimento foi conduzida na Estação de Piscicultura Matão, em dois viveiros escavados de terra, com área total de 4.100 metros quadrados, situado no município de Florestópolis, Paraná. Posteriormente, na segunda fase, deu-se continuidade ao experimento em 16 tanques-rede da Estação de Piscicultura Estância Alvorada, situada no município de Porecatu, PR. Essa piscicultura está instalada em águas do reservatório da usina hidrelétrica (UHE) Represa Capivara, na Bacia do
Paranapanema, divisa do estado de São Paulo e Paraná.

\section{Primeira fase experimental}

Os dois viveiros foram povoados com 57.000 juvenis de tilápia do Nilo, Oreochromis niloticus, variedade local com peso médio de $14,0 \pm 1,42$ gramas. Anteriormente estes animais foram classificados no laboratório da Estação de Piscicultura Matão. Na primeira fase os peixes foram alimentados com ração comercial extrusada com $42 \%$ de proteína bruta e em pellets de 2,0 mm (Tabela 1).

A primeira fase do experimento teve duração de 10 dias. $\mathrm{O}$ viveiro controle recebeu a dieta comercial tratada com óleo de soja comercial (02 litros/ $25 \mathrm{~kg}$ de ração). O viveiro experimental recebeu a mesma dieta comercial tratada com óleo de soja $(+250$ gramas de ergosan, $1 \%$ da ração, Intervet ScheringPlough). O ergosan foi incorporado ao óleo de soja com auxílio de um liquidificador. Foi utilizada uma taxa de arraçoamento diário de $20 \%$ da biomassa dos peixes.

Durante a primeira fase experimental foram repostas somente as águas perdidas por evaporação e infiltração. O oxigênio dissolvido e a temperatura da água foram avaliados diariamente por meio de um oxímetro YSI 550; o pH, a condutividade elétrica e os sólidos totais com um equipamento digital Hana; a alcalinidade, dureza, amônia e nitrito com o uso de um polikit da Alfa-tecnoquímica e a transparência com o disco de Secchi. Diariamente foram avaliados temperatura e oxigênio e semanalmente os outros parâmetros. 
Tabela 1. Composição química das dietas comerciais utilizadas.

\begin{tabular}{lcc}
\hline Item & Ração 42 \% de PB & Ração 36\% de PB \\
\hline Proteína bruta (min. \%). & 42,0 & 36,0 \\
Umidade (max. \%) & 12,0 & 12,0 \\
Fibra bruta (max. \%) & 3,0 & 3,5 \\
Matéria Mineral (máx. \%). & 15,0 & 9,7 \\
Extrato Etéreo (min. \%). & 4,0 & 4,0 \\
Cálcio (máx. \%). & 3,5 & 2,5 \\
Fósforo (min. \%). & 1,2 & 1,2 \\
\hline
\end{tabular}

Suplemento vitamínico mineral (níveis de garantia por quilograma do produto): Vit A: 3.000 UI, Vit D3: 1.500 UI, Vit E: $120 \mathrm{mg}$, Vit K: $6 \mathrm{mg}$, Tiamina: $18 \mathrm{mg}$, Riboflavina: $24 \mathrm{mg}$, Piridoxina: $18 \mathrm{mg}$, Ácido pantotênico: $72 \mathrm{mg}$, Ácido nicotínico: $108 \mathrm{mg}$, Biotina: 0,2 mg, Ácido Fólico: $3 \mathrm{mg}$, Vitamina B12: 0,015 mg, Vitamina C: $450 \mathrm{mg}$, Colina: 1.200 $\mathrm{mg}$, Inositol: $150 \mathrm{mg}$, Zinco: $80 \mathrm{mg}$, Ferro: $60 \mathrm{mg}$, Manganês: $40 \mathrm{mg}$, Iodo: $4 \mathrm{mg}$, Cobre: $8 \mathrm{mg}$, Cobalto: 0,8 mg, Cromo: 0,6 mg, Selênio: $0,17 \mathrm{mg}$.

Após 10 dias da primeira fase, os peixes foram despescados com arrastões de 40 metros de comprimento e malha de $10 \mathrm{~mm}$ e levados para o laboratório de depuração com o auxílio de um trator, em tambores de transporte de 50 litros. Foram mantidos por aproximadamente 04 horas no laboratório, em 16 caixas de 1.000 litros em processo de depuração por água corrente e aeração suplementar com uso de sopradores de ar. Foram então, transportados em 03 caixas de 1.000 litros em duas viagens até a Estação de Piscicultura Estância Alvorada.

\section{Segunda fase experimental}

A segunda fase teve também a duração de 10 dias, sendo utilizados 16 TRs de arame galvanizado $3 / 4$ polegada revestido em PVC $(2 \times 2 \times 2 \mathrm{~m})$ da Piscicultura Estância Alvorada. Foram utilizados 54.126 juvenis de tilápias com peso médio de 40,63 g. Todos os tanques-rede foram povoados com 3.382 peixes e a taxa de mortalidade avaliada diariamente durante 10 dias. Os peixes dos tanques-rede controle receberam dieta comercial somente tratada com óleo de soja e os dos tanques-rede experimentais, dieta tratada com óleo de soja e ergosan na dose de 1\% da ração. Nessa fase os peixes foram alimentados com ração comercial extrusada contendo $36 \%$ de proteína bruta e na forma de pellets de $3,0 \mathrm{~mm}$ (Tabela 1).

O protocolo utilizado no tratamento dos peixes com ergosan dez dias antes e após o manejo estressor, assim como a dose de $1 \%$ de ergosan na ração, utilizados no presente estudo, está de acordo com o recomendado pelos Médicos Veterinários especializados em aquicultura da Intervet ScheringPlough Animal Health do Brasil.

Os resultados obtidos fora submetidos 'a análise de variância (ANOVA) e complementada pelo teste " $t$ " de Student e o teste de Student Newman Keuls (SNK).

\section{Resultados e Discussão}

Os valores médios dos parâmetros físicoquímicos da água dos viveiros e do reservatório UHE Capivara apresentados na Tabela 02 encontravamse dentro do recomendado para o cultivo de tilápia do Nilo, permitindo bom desempenho dos peixes de acordo com Brune e Tomasso (1991); Boyd (1995) e Kubitza (2003). 
Tabela 2. Valores médios dos parâmetros físico-químicos da água do viveiro controle, viveiro experimental e da represa UHE Capivara.

\begin{tabular}{lccc}
\hline Variáveis & $\begin{array}{c}\text { Viveiro Controle } \\
\text { (Média } \pm \text { SE) }\end{array}$ & $\begin{array}{c}\text { Viveiro Experimental } \\
\text { (Média } \pm \text { SE) }\end{array}$ & $\begin{array}{c}\text { Represa Capivara } \\
\text { (Média } \pm \text { SE) }\end{array}$ \\
\hline Temperatura da água $\left({ }^{\circ} \mathrm{C}\right)$ & $26,55 \pm 4,62$ & $27,25 \pm 5,42$ & $22,45 \pm 3,60$ \\
Oxigênio dissolvido $(\mathrm{mg} / \mathrm{L})$ & $6,52 \pm 1,34$ & $6,72 \pm 1,44$ & $8,28 \pm 1,45$ \\
pH & $7,41 \pm 0,43$ & $7,19 \pm 0,33$ & $7,78 \pm 0,54$ \\
Alcalinidade (mgCaCO $/ \mathrm{L})$ & $59,64 \pm 9,72$ & $58,44 \pm 8,62$ & $31,64 \pm 2,72$ \\
Dureza (mg/ L) & $65,54 \pm 10,72$ & $64,41 \pm 9,62$ & $43,02 \pm 5,62$ \\
Condutividade $(\mathrm{mmhos} / \mathrm{cm})$ & $120,76 \pm 19,71$ & $145,61 \pm 24,61$ & $88,52 \pm 10,81$ \\
Sólidos totais (ppt) & $0,05 \pm 0,02$ & $0,09 \pm 0,03$ & $0,03 \pm 0,01$ \\
Amônia total (mg/ L) & $0,09 \pm 0,08$ & $0,10 \pm 0,09$ & $0,08 \pm 0,07$ \\
Nitrito (mg/ L) & $0,10 \pm 0,01$ & $0,11 \pm 0,02$ & $0,08 \pm 0,05$ \\
Transparência pelo disco & & & $157,50 \pm 20,52$ \\
de Secchi (cm) & $47,50 \pm 14,52$ & $28,50 \pm 11,42$ & \\
\hline
\end{tabular}

Fonte: Elaborada pelos autores.

Após a instalação dos peixes aos tanquesrede, no reservatório UHE Capivara ocorreram vento forte, chuvas torrenciais, raios e trovoadas, o que determinou uma diminuição acentuada de temperatura da água e forte stress aos animais. Nos viveiros escavados, os peixes permaneceram com água a $26,5{ }^{\circ} \mathrm{C}$ e nos tanques-rede permaneceram com água a $22,4{ }^{\circ} \mathrm{C}$. De acordo Kubitza (2009a) e Ayrosa et al. (2009) diminuições bruscas de temperatura com forte oscilação diária prejudicam a resistência imunológica dos peixes e favorecem o desenvolvimento e manifestação dos agentes patogênicos com mortalidade de peixes.

Para Ayrosa et al. (2009) as consequências da mudança climática, depende das condições naturais do ambiente de criação e da capacidade de adaptação do manejo produtivo, sendo distintas para os viveiros escavados e tanques-rede. Nos viveiros escavados é possível uma maior intervenção por parte do produtor, desde que adotadas tecnologias apropriadas. Já em reservatórios de usina hidrelétrica de grande porte a interferência do aquicultor é menos efetiva.

Segundo esses mesmos autores as alterações de temperatura da água de grandes reservatórios, dependem do volume do reservatório, profundidade do local de instalação dos tanques-rede, tempo de residência da água do reservatório, grau de eutrofização, estratificação da coluna de água e afirmam que as fortes alterações de temperatura da água ocasionam estresse. Para Pavanelli, Eiras e Takemoto (2002), alterações bruscas de temperatura da água do cultivo são capazes de constituir uma grave ameaça ao sucesso das explorações comerciais de peixes na piscicultura.

Os valores médios de desempenho dos peixes dos dois viveiros escavados durante a primeira fase do experimento estão apresentados na Tabela 03. Foi observada melhor conversão alimentar para os peixes do viveiro experimental $(1,41: 1,0)$ quando comparado aos do viveiro controle $(1,43$ : $1,0)$. Maior ganho de peso e maior eficiência alimentar de peixes tratados com alginato de sódio 
também foi encontrado por Yeh et al. (2.008) em Epinephelus coioides. Maior taxa de crescimento foi relatado por Vollstad et al. (2006) em larvas de bacalhau do atlântico Gadus morhua e spotted wolfish (Anarhichas minor) alimentadas com alginatos na ração. Utilizando o alginato extraído da alga marinha Durvillaea Antarctica, Skjermo et al. (2006) demonstraram maior ganho de peso no bacalhau do atlântico Gadus morhua.

Tabela 3. População inicial, peso médio inicial $(\mathrm{g})$, biomassa inicial $(\mathrm{kg})$, população final, peso médio final (g), biomassa final $(\mathrm{kg})$, ganho em biomassa, conversão alimentar e sobrevivência (\%) no viveiro escavado de terra controle e no viveiro experimental povoados com juvenis de tilápia do Nilo, Oreochromis niloticus.

\begin{tabular}{lll}
\hline & Viveiro Controle & Viveiro experimental \\
\hline População inicial de peixes & 26.000 & 31.000 \\
Peso médio inicial $(\mathrm{g})$ & $14,0 \pm 1,42$ & $14,0 \pm 1,42$ \\
Biomassa inicial $(\mathrm{kg})$ & 364,00 & 440,2 \\
População final de peixes & 23.551 & 30.575 \\
Peso médio final (g) & $41,11 \pm 3,44$ & $40,15 \pm 3,21$ \\
Biomassa final $(\mathrm{kg})$ & 968,11 & $1.227,60$ \\
Ganho em biomassa $(\mathrm{kg})$ & 604,11 & 793,60 \\
Conversão Alimentar & $1,43: 1,0$ & $1,41: 1,0$ \\
Sobrevivência dos peixes $(\%)$ & 90,58 & 98,63 \\
\hline
\end{tabular}

Fonte: Elaborada pelos autores.

Os polissacarídeos sulfatados de Botryocladia occidentalis incorporados na dieta de pós-larvas de tilápias, de acordo Rebouças et al. (2002), resultou em aumento significativo no crescimento dos peixes. Resultados similares foram encontrados em tilápia do Nilo por Farias et al. (2004) e em carpa comum por Huttenhuis et al. (2006). Segundo Kubitza (2009a, 2009b) no cultivo da tilápia do Nilo em piscicultura de viveiro escavado deve-se fazer uso de rações nutricionalmente completas, almejando uma conversão alimentar de 1:1.

Segundo alguns pesquisadores, dietas suplementadas com ácidos algínicos não interferiram na performance de crescimento do salmão Salmo salar (GABRIELSEN; AUSTRENG, 1998), do robalo, Dicentrarchus labrax (BAGNI et al., 2005), bem como dietas suplementadas com beta glucanos no Dentex dentex (EFTHIMIOU, 1996) e com vitamina C e vitamina E no salmão Salmo salar em temperaturas de água de 22 oC
(HARDIE; FLETCHER; SECOMBES, 1990, 1991), respectivamente. Da mesma forma, dietas suplementadas com lipossacarídeos não interferiram no crescimento de salmão Salmo salar (GUTTVIK et al., 2002). Entretanto, a redução da temperatura da água para $13 \mathrm{oC}$ (temperatura de inverno) resultou em efeito positivo sobre o crescimento de robalo Dicentrarchus labrax após a administração oral de ácidos algínicos (BAGNI et al., 2005).

Foi encontrado maior taxa de sobrevivência dos peixes no viveiro experimental $(98,63 \%)$ quando comparado aos do viveiro controle $(90,58)$ durante a primeira fase do experimento. Resultado similar em bacalhau do atlântico Gadus morhua, com o uso de alginatos, foram descritos por Vollstad et al, (2006) e Skjermo et al. (2006).

Maiores taxas de sobrevivência e resistência dos peixes a infecção experimental pelo Streptococcus sp e iridovirus foram encontradas por Yeh et al. 
(2008) em Epinephelus coioides tratados com alginato de sódio na dose de 1,0 e $2,0 \mathrm{~g}$ por $\mathrm{kg}$ de ração. Chiu et al. 2008, demonstraram também maior taxa de sobrevivência em juvenis de Epinephelus fuscoguttatus, contra a infecção experimental pelo Streptococcus sp. e iridovirus em peixes tratados com alginato de sódio nas doses de 1,0 e 2,0 g por $\mathrm{kg}$ de ração. Esses autores demonstraram aumento de parâmetros imunes não específicos, tais como, aumento da atividade da lisozima, atividade fagocítica, hemaglutinação e aumento da atividade do superóxido dismutase.

De acordo com Schering-Plough Animal Health Corp (2009), os alginatos favorecem a utilização de programas preventivos estratégicos frente aos principais desafios de ordem ambiental, sanitária e de manejo encontrados nas criações de larvas, alevinos e juvenis de peixes. Alem disto, as boas práticas de manejo associadas `a complementação alimentar diferenciada dos animais, vem assumindo uma importância cada vez maior no sucesso produtivo dos empreendimentos aqüícolas de todo o mundo. Para Bagni et al. (2005) deve-se evitar o uso de antibióticos e hormônios e incentivar o uso de produtos naturais como os alginatos nos tratamentos preventivos dos peixes em empreendimentos aquícolas.

Os ácidos algínicos induzem a resposta imune não específica a uma série de patógenos, sendo capaz de aumentar a resistência dos peixes a infecção, aumentar a atividade metabólica e a proliferação de linfócitos e macrófagos, aumentar a produção de citosinas e lisozima, favorecer as células a restabelecerem a integridade celular e aumentar a produção de muco. São também capazes de realçar a resposta imune em animais com sistema imune debilitado ou em desenvolvimento (BAGNI ect al., 2005; BRICKNELL; DALMO, 2005; CARNEVALI; SMITH, GIOACCHINI, 2006).

Gopalakannan e Arul (2006) demonstraram que a administração oral dos imunoestimulantes levamisol, quitosana e quitina em carpa comum,
Cyprinus carpio, aumentou significativamente a sobrevivência dos animais após infecção com Aeromonas hydrophila. O melhor resultado foi obtido com o polissacarídeo quitosana. Além disso, a administração oral dos mesmos resultou em maior ganho de peso dos peixes. Menor taxa de mortalidade também foi encontrada por Huttenhuis et al. (2006) em larvas e juvenis de carpa comum alimentadas com alginatos na dieta e infectada experimentalmente pelo vibrio anguillarum.

Na segunda fase do experimento, a média dos dois tanques-rede (TRs) do grupo controle na primeira e segunda fase (CC) apresentou 12,21 \pm $4,01 \%$ de mortalidade dos peixes. O grupo de 04 TRs controle na primeira fase e experimental na segunda (CE) apresentou média de mortalidade de $10,13 \pm 2,73 \%$. O grupo de 04 TRs experimental na primeira e segunda fase (EE) apresentou $13,93 \pm$ $4,84 \%$ e o grupo de 06 TRs experimental na primeira fase e controle na segunda (EC), valores de 14,65 \pm $5,51 \%$. Não houve diferenças significativas de taxa de mortalidade entre os tratamentos. No presente estudo, a diminuição brusca de temperatura, provavelmente, foi o fator responsável pelos índices de mortalidade encontrados na segunda etapa do experimento, e o ergosan não se mostrou eficaz na redução dessas taxa de mortalidade.

A piscicultura Estância Alvorada conta atualmente com 600 tanques-rede alojados na UHE Capivara e em outros manejos de transferência de juvenis de tilápia de viveiros escavados para tanquesrede, com a mesma equipe de trabalho e mesmas condições de transporte, e têm obtido resultados mais satisfatórios para a taxa de mortalidade. Em média, essa piscicultura obtém valores inferiores a 5 $\%$ de mortalidade de peixes. Desta forma, acreditase que a despesca, a depuração, o transporte e o confinamento dos peixes nos tanques-rede não sejam os principais responsáveis pelos altos índices de mortalidade $(10,13 \%$ a $14,65 \%)$ encontrados no presente estudo e sim a presença de vento forte, chuvas e trovoada associada a diminuição acentuada de temperatura da água nos primeiros 
dias de alojamento dos animais.

A maior mortalidade de juvenis de tilápia do Nilo ocorreu entre o terceiro e sétimo dias após o manejo. Após 12 dias de realizado a instalação dos animais não ocorreu mais mortes de peixes nos tanques-rede. Com a presença de vento no reservatório, forma-se ondas capazes de encobrir o tanque-rede, impedindo em vários momentos do dia, o acesso de barco e a oferta de ração aos peixes. As grandes ondas obrigam os peixes a nadarem contra a correnteza e em vários momentos os animais são projetados contra as telas de arame, o que provoca uma série de ferimentos, com perda de escamas nos peixes.

De acordo com Figueiredo Nóbrega Netto e Leal (2009) a manutenção de condições ambientais, manejo adequado e a implementação de práticas de biossegurança são os principais procedimentos para minimizar o impacto e impedir a mortalidade de peixes na piscicultura. O manejo de despesca, o transporte, a depuração, o confinamento dos animais nos tanques-rede são fatores estressante, capazes de comprometer o sistema imune dos peixes e propiciar a instalação de parasitas e agentes infecciosos (BARBER, 2007; HARMON, 2009).

Araujo (2006) demonstrou que a incorporação de $0,1 \mathrm{mg} / \mathrm{g}$ de polissacarídeo sulfatado, extraído da macroalga marinha vermelha Gracilaria caudata, na ração de tilápia do Nilo submetidas à reversão sexual foi capaz de conferir maior resistência aos peixes, quando eles foram submetidos 'a condições de estresse de transporte por duas horas.

Os alginatos não interferiram na taxa de mortalidade em larvas de bacalhau do atlântico (Gadus morhua) e spotted wolfish (Anarhichas minor) alimentadas com alginatos na ração em condições de cultivo e/ou infectadas pela bactéria Aeromonas salmonicida (VOLLSTAD et al., 2006).

\section{Conclusões}

A utilização do alginato ergosan na ração proporcionou melhor conversão alimentar e maior taxa de sobrevivência dos peixes em viveiros escavados.

A incorporação de ergosan na ração não foi eficiente na redução da taxa de mortalidade dos peixes.

O uso de alginatos na ração pode ser indicado em períodos de inverno em peixes tropicais, onde as respostas imunes estejam deprimidas. A dose ótima, o número de dias de tratamento e o período do ano, bem como a viabilidade econômica da incorporação de alginatos na ração de peixes de água tropical deve ser mais bem estudado.

\section{Agradecimentos}

À Universidade Estadual de Londrina, Intervet Schering-Plough, Piscicultura Matão e a Piscicultura Estância Alvorada.

\section{Referências}

ARAUJO, G. S. O efeito imunoestimulante dos polissacarídeos sulfatados da alga marinha vermelha gracilaria caudata na reversão sexual de tilápia do Nilo, Oreochromis niloticus (Linnaeus, 1766) em condições adversas. 2006. Dissertação (Mestrado em Engenharia de Pesca) - Universidade Federal do Ceará, Fortaleza, Ceará.

AYROSA, D. M. M. R.; FURLANETO, F. P. B.; AYROSA, L. M. S.; AYROSA, M. R. As mudanças climáticas e a aqüicultura: os novos desafios que vêm por ai. Panorama da Aqüicultura, Rio de Janeiro, v. 19, n. 111, p. 46-52, jan./fev. 2009.

BAGNI, M.; ROMANO, N.; FINOIA, M. G.; ABELLI, L.; SCAPIGLIATI, G.; TISCAR, P. G.; SARTI, M.; MARINO, G. Short and long term effects of a dietary yeast $\beta$-glucan (Macrogard) and alginic acid (Ergosan) preparation on immune response in sea bass (Dicentrarchus labrax). Fish \& Shellfish Immunology, v. 18, n. 4, p. 311-325, 2005.

BARBER, I. Review: parasites, behavior and welfare in fish. Applied Animal Behavior Science, v. 104, p. 251264, 2007.

BARCELlos, L. J. G. Policultivo de jundiás, tilápias e carpas: uma alternativa de produção para a piscicultura 
rio-grandense. Passo Fundo, RS: Editora Universitária, UPF, 2006.

BARCELLOS, L. J. G.; KREUTZ, L. C.; QUEVEDO, R. M.; FIOREZE, I.; SOSO, A. B.; CERICATO, L.; FAGUNDES, M.; CONRAD, J.; BALDISERRA, R.; BRUSCHI, A.; RITTER, F. Nursery rearing of jundiá, Rhamdia quelen in cages: cage type, stoking density and stress response to confinement. Aquaculture, Amsterdan, v. 232, p. 383-394, 2004.

BARCELLOS, L. J. G.; NICOLAIEWSKY, S.; SOUZA, S. M. G.; LULHIER, F. The effects of stoking density and social interaction on the acute stress response and body weight in Nile tilapia (Oreochromis niloticus) previously exposed to chronic stress. Aquaculture Research, v. 29, p. 887-892, 1999.

BEVERIDGE, M. C. M.; MCANDREW, B. J. Tilapias: biology and exploitation. Dordrecht, The Netherlands: Kluwer Academic Publishers, 2000. 505 p.

BOYD, C. E. Bottom soils, sediment, and pond aquaculture. New York: Chapman and Hall, 1995.

BRICKNELL, I.; DALMO, R. A. The use of immunostimulants in fish larval aquaculture. Fish $e$ Shellfish Imunology, v. 18, n. 4, p. 290-310, 2005.

BRUNE, D. E.; TOMASSO, J. R. Aquaculture and water quality. Baton Rouge: The World Aquaculture Society, $1991.606 \mathrm{p}$.

CARNEVALI, O.; SMITH, P.; GIOACCHINI, G. The effects of AquaVac Ergosan on the innate immunosystem and on the stress tolerance of trout. In: AQUACULTURE EUROPE, 2006, Fortezza da Basso Convention Centre, Florence, Italy. Anais... Florence, European Aquaculture Society, 2006, p. 194.

CHIU, S.-T.; TSAI, R.-T.; HSU, J.-P.; LIU, C.-H.; CHENG, W. Dietary sodium alginate administration to enhance the non-specific immune responses, and disease resistance of the juvenile grouper. Epinephelus fuscoguttatus Aquaculture, v. 277, p. 66-72, 2008.

CYRINO, J. E. P.; URBINATI, E. C.; FRACALOSSI, D. M.; CASTAGNOLLI, N. Tópicos especiais em piscicultura de água doce tropical intensiva. São Paulo: TecArt, Sociedade Brasileira de Aquicultura e Biologia Aquática, 2004.

EFTHIMIOU, S. Dietary intake of b-1, 3/1, 6 glucans in juvenile dentex (Dentex dentex), sparidae: effects on growth performance, mortalities and non-specific defense mechanisms. Journal of Applied Ichthyolology, Rome, v. 12, p. 1-7, 1996.

FAO - FOOD AND AGRICULTURE ORGANIZATION OF THE UNITED NATIONS. Fisheries Department,
Yearbook of fishery statistic. Roma: FAO, 2007.

FARIAS, W. R. L.; REBOUÇAS, H. J.; TORRES, V. M.; RODRIGUES, J. A. G.; PONTES, G. C.; SILVA, F. H. O. S.; SAMPAIO, A. H. Enhancement of growth in tilapia larvae (Oreochromis niloticus) by sulfated D-galactans extracted from the red marine alga Botryocladia occidentalis. Revista Ciência Agronômica, Fortaleza, CE, v. 35, p. 189-195, 2004. (Especial).

FIGUEIREDO, H. C. P.; NÓBREGA NETTO L.; LEAL, C. A. G. Streptococcus iniae: um grande vilão da aqüicultura mundial identificado no Brasil. Panorama da Aqüicultura, Rio de Janeiro, v. 19, n. 112, p. 26-29, mar./ abr. 2009.

GABRIELSEN, B. O.; AUSTRENG, E. Growth, product quality and immune status of Atlantic salmon, Salmo salar L., fed wet feed with alginate. Aquaculture Research, v. 29, p. 397-401, 1998.

GIOACCHINI, G.; SMITH, P.; CARNEVALI, O. Effects of Ergosan on the expression of cytokine genes in the liver of juvenile rainbow trout (Oncorhynchus mykiss) exposed to enteric red mouth vaccine. Veterinary Immunology and Immunopathology, v. 123, p. 215-222, 2008.

GOPALAKANNAN, A.; ARUL, V. Immunomodulatory effects of dietary intake of chitin, chitosan and levamisole on the immune system of Cyprinus carpio and control of Aeromonas hydrophila infection in ponds. Aquaculture, Amsterdam, v. 255, p. 179-187, 2006.

GUTTVIK,A.; PAULSEN, B.;DALMO, R.A.;ESPELID, S.; LUND, V.; BOGWALD, J. Oral administration of lipopolysaccharide to Atlantic salmon (Salmo salar) fry. Uptake, distribution, influence on growth and immune stimulation. Aquaculture, Amsterdam, v. 214, p. 35-53, 2002 .

HARDIE, L. J.; FLETCHER, T. C.; SECOMBES, C. J. The effect of dietary vitamin $C$ on the immune response of Atlantic salmon (Salmo salar). Aquaculture, Amsterdam, v. 87, n. 1, p. 1-13, 1990.

. The effect of dietary vitamin $\mathrm{E}$ on the immune response of Atlantic salmon (Salmo salar). Aquaculture, Amsterdam, v. 95, n. 3/4, p. 201-214, 1991.

HARMON, T. S. Methods for reducing stressors and maintaining water quality associated with, live fish transport in tanks: a review of the basics. Reviews in Aquaculture, v. 1, p. 58-66, 2009.

HUTTENHUIS, H. B.T.; RIBEIRO, A. S. P.; BOWDEN, T. J.; VAN BAVEL, C.; TAVERNE-THIELE, A. J.; ROMBOUT, J. H. W. M. The effect of oral immunostimulation in juvenile carp (Cyprinus carpio L.) Fish \& Shellfish Immunology, v. 21, p. 261-271, 2006. 
KUBITZA, F. Manejo na produção de peixes; parte 05: boas práticas de manejo sanitário. Panorama da Aqüicultura, Rio de Janeiro, v. 19, n. 112, p. 15-23, mar./ abr. 2009a.

Manejo na produção de peixes; parte 06: boas práticas nas despescas, manuseio e classificação dos peixes. Panorama da Aqüicultura, Rio de Janeiro, v. 19, n. 113, p.14-23, maio/jun. 2009b.

Qualidade da água no cultivo de peixes e camarões. Jundiaí, SP: Fernando Kubitza, 2003. 229 p.

Tilápia: tecnologia e planejamento na produção comercial. Jundiaí, SP: Fernando Kubitza, 2000. 289 p.

MEURER, F.; HAYASHI, C.; BOSCOLO, W. R. Influência do processamento da ração no desempenho e sobrevivência da tilápia do Nilo durante a reversão sexual. Revista Brasileira de Zootecnia, Viçosa, v. 32, n. 2, p. 262-267, 2003.

PARK, H. H.; JEONG, H. D. Enhanced resistence against Edwardsiella tarda in tilapia (O. niloticus) by administration of protein-bound polysaccharidae. Aquaculture, Amsterdam, v. 143, n. 3, p. 135-143, 1996.

PAVANELLI, G. C.; EIRAS, J. C.; TAKEMOTO, R .M. Doenças de peixes: profilaxia, diagnóstico e tratamento. Maringá, PR: EDUEM, 2002. 305 p.

PEDDIE, S.; ZOU, J.; SECOMBES, C. J. Immunostimulation in the rainbow trout (Oncorhynchus mykiss) following intraperitoneal administration of Ergosan. Veterinary Immunology and Immunopathology, v. 86, p. 101-113, 2002.

REBOUÇAS, H. J.; TORRES, V. M.; PONTES, G. C.; SILVA, F. H. O.; RODRIGUES, J. A. G.; NETO, J. T. B. B.; FARIAS, W. R. L. Efeito da adição do polissacarídeo sulfatado da alga marinha Botryocladia occidentalis na ração de tilápia do Nilo, Oreochromis niloticus, submetidos à reversão sexual. In: SIMPÓSIO BRASILEIRO DE AQÜICULTURA, 12., 2002, Goiânia, GO. Anais...Goiânia: Editora Simbraq, 2002. p. 2.

SAKAI, M. Current research status of fish imunoestimulants. Aquaculture, Amsterdam, v. 172, n. 1, p. 63-92, 1999.

SCHERING-PLOUGH Animal Health Corp. Aquaculture Centre, 556 Morris Ave Summit NJ 07901 USA. Disponível em: <http://www.spaquaculture.com>. Acesso em: 20 ago. 2009.

SKJERMO, J.; BERGH, O. High-M alginate immunostimulation of atlantic halibut (Hippoglossus hippoglossus L.) larvae using Artemia for delivery increases resistance against vibriosis. Aquaculture, Amsterdam, v. 238, p. 107-113, 2004.
SKJERMO, J.; STORSETH, T. R.; HANSEN, K.; HANDA,A., OIE G. Evaluation of $\beta-(1 \rightarrow 3,1 \rightarrow 6)$-glucans and High-M alginate used as immunostimulatory dietary supplement during first feeding and weaning of Atlantic cod (Gadus morhua L.) Aquaculture, Amsterdam, v. 261, p. 1088-1101, 2006.

TINMAN, S.; KELVIN, F.; CARVALHO-FILHO, J. Effect of long-term oral administration of peptidoglucan (PG- Ajinomoto product) on growth rate and imunoestimulation response of hybrid tilapia $(O$. aureus $X O$. niloticus). INTERNATIONAL SYMPOSIUM ON TILAPIA AQUACULTURE, 5., 2000, Rio de Janeiro. Proceedings... Rio de Janeiro: Editora Insta, v. 2, p. 524532, 2000.

VADSTEIN, O. The use of immunostimulation in marine larviculture: possibilities and challenges. Aquaculture, Amsterdam, v. 155, p. 401-417, 1997.

VOLLSTAD, D.; BOGWALD, J.; SEROD, O. G.; $\mathrm{DALMO}, \mathrm{R}$. A. Influence of high-M alginate on the growth and survival of Atlantic cod (Gadus morhua L.) and spotted wolfish (Anarhichas minor Olafsen) fry. Fish \& Shellfish Immunology, v. 20, p. 548-561, 2006.

YEH, S.-P.; CHANG, C.-A.; CHANG, C.-Y.; LIU, C.H.; CHENG, W. Dietary sodium alginate administration affects fingerling growth and resistance to Streptococcus sp. and iridovirus, and juvenile non-specific immune responses of the orange-spotted grouper. Epinephelus coioides Fish \& Shellfish Immunology, v. 25, p. 19-27, 2008. 